\title{
Effects of Antifungal Drugs on Proliferation Signals in Candida albicans
}

\author{
Mitsuo Matsuki, Hatsuki Kanatsu, Toshihiko Watanabe,* Ayako Ogasawara, Takeshi Mikami, and \\ Tatsuji Matsumoto
}

Department of Microbiology, Tohoku Pharmaceutical University; 4-4-1 Komatsushima, Aoba-ku, Sendai 981-8558, Japan. Received October 25, 2005; accepted February 2, 2006; published online February 6, 2006

\begin{abstract}
The sensitivity of Candida albicans to antifungal drugs when cultured under aerobic and anaerobic conditions was measured. Ciclopirox olamine and siccanin were more effective under aerobic than under anaerobic conditions. Terbinafine, neticonazole and amphotericin B showed the same antifungal activity under both aerobic and anaerobic conditions. None of these antifungal activities were affected by the $\mathrm{pH}$ conditions. Terbinafine inhibited the elongation of hyphae, while neticonazole and amphotericin $B$ induced proliferation of the yeast form. The expression of RAS1, EFG1 and CPH1 mRNAs was inhibited by these drugs. These results suggested that the inhibition of hyphal formation might be caused by disruption of the RAS1-signal pathway.
\end{abstract}

Key words Candida albicans; ciclopirox olamine; siccanin; terbinafine; neticonazole; amphotericin B

Candida albicans is an opportunistic fungus which generally exists in the oral cavity, skin, vagina and intestinal organs, and is also one of the causes of superinfection. ${ }^{1)}$ The antifungal drugs described below are applied to treat superficial and deep-seated infections.

The arylamine antimycotic terbinafine inhibits squalene epoxidase in fungi. ${ }^{2)}$ Terbinafine induces the accumulation of squalene and interrupts the synthesis of ergosterol. Neticonazole is an antifungal drug of azole type that inhibits ergosterol synthesis. ${ }^{3)}$ The polyene antimycotic amphotericin B binds to fungal membranes and obstructs the function of the membranes. ${ }^{4)}$ Ciclopirox olamine inhibits the membrane transfer system by interrupting $\mathrm{Na}^{+} \mathrm{K}^{+}$ATPase. ${ }^{5)}$

C. albicans is a dimorphic fungus which transforms from yeast to a hyphal form depending on the growth conditions. ${ }^{6}$ AOX1, an alternative oxidase in C. albicans, seems to be related to the respiration system. ${ }^{7}$ C. albicans has RAS1 protein, which activates factors involved in hyphal formation signaling, such as EFG1 and CPH1. ${ }^{8)}$ There may be differences in the metabolic and respiratory systems between yeast and hyphae cells, but the sensitivity of $C$. albicans to antifungal drugs has not been clarified. Examination of the sensitivity is important to do a suitable treatment of Candida infection.

In this study, we clarified the sensitivity of $C$. albicans to antifungal drugs under various culture conditions and the effects of the drugs on the growth form of C. albicans.

\section{MATERIALS AND METHODS}

Fungus C. albicans NIH A207, TIMM1768, JCM2076 and TIMM2640 were cultured at $27^{\circ} \mathrm{C}$ for $24 \mathrm{~h}$ in Sabouraud's medium.

Reagents Ciclopirox olamine (Azwell), siccanin (Sankyo), amphotericin B (Bristol-Myers Squibb), neticonazole (SSP) and terbinafine (Novartis Pharma) were used in this study.

Sensitivity of $C$. albicans to Antifungal Drugs C. albicans cells $\left(1 \times 10^{5}\right.$ cells $/ \mathrm{ml}$ in RPMI1640 medium) were mixed with antifungal drugs and incubated at $37^{\circ} \mathrm{C}$ for $24 \mathrm{~h}$ under $5 \% \mathrm{CO}_{2}$. After the incubation, the amount of C. albicans was measured as the optical density at $620 \mathrm{~nm}$. The growth form of C. albicans cells was assessed by photo- graphing the cultures with a camera attached to an IX51 microscope (Olympus).

Quantification of mRNAs in C. albicans C. albicans $\left(1 \times 10^{5}\right.$ cells $/ \mathrm{ml}$ in RPMI1640 medium) was incubated at $37^{\circ} \mathrm{C}$ for $6 \mathrm{~h}$ under $5 \% \mathrm{CO}_{2}$. After the incubation, the cells were harvested by centrifugation, and re-suspended in $\mathrm{Zy}$ molyase buffer $[10 \mathrm{mg} / \mathrm{ml}$ Zymolyase $100 \mathrm{~T}$ (Seikagaku), $0.9 \mathrm{M}$ sorbitol, 0.1 м EDTA-Na, 50 mм DTT (pH 7.5)] at $37^{\circ} \mathrm{C}$ for $20 \mathrm{~min}$. Total RNA was extracted using a Total RNA Purification Kit MagExtractor (Toyobo). To prepare cDNA, total RNA was mixed with dNTP mix (Toyobo). Random hexamers (Roche Diagnostics) were added to the mixture and incubated at $70^{\circ} \mathrm{C}$ for $3 \mathrm{~min}$. M-MLV Reverse Transcriptase (Ambion), 1:10 the final reaction-mixture volume of $10 \times \mathrm{RT}$ buffer (Ambion) and RNase inhibitor (Promega) were added to this mixture and incubated at $42^{\circ} \mathrm{C}$ for $1 \mathrm{~h}$. The reaction was terminated by heating at $92^{\circ} \mathrm{C}$ for $10 \mathrm{~min}$ and the resulting mixture was used as cDNA solution. The relative expression of the target gene in the cDNA library was analyzed using the 7500 Real Time PCR System (Applied Biosystems). Gene arrangements were determined using the Entrez System of the National Center for Biotechnology Information (U.S.A.). PCR primers and the TaqMan MGB probe were designed using Primer Express (Applied Biosystems). These sequences are shown in Table 1. The results are shown as relative expression compared to $18 \mathrm{~S}$ rRNA.

Statistical Analysis Values are shown as means \pm S.E., and statistical analysis of these data was performed using the Student's $t$-test. $p<0.05$ was considered significant.

Table 1. Primer Sequences

$\begin{array}{ll}\text { RAS1 (sense) } & \text { GACCCAACTATTGAAGATTCTTATCGT } \\ \text { RAS1 (antisense) } & \text { AACCCTTCACCAGTTCTCATATATTGT } \\ \text { RAS1 (MGB-probe) } & \text { TTTAGATACTGCTGGACAAGA } \\ \text { EFG1 (sense) } & \text { GTTGAACGCCTCGAGCACTT } \\ \text { EFG1 (antisense) } & \text { TTTCATCTTCCCACATGGTAGTTG } \\ \text { EFG1 (MGB-probe) } & \text { CAATTCCAACCACCAGG } \\ \text { CPH1 (sense) } & \text { CGAGAACCAGCATTATCATTCCA } \\ \text { CPH1 (antisense) } & \text { GAGTTTCCATGTGTTTACCCAATTG } \\ \text { CPH1 (MGB-probe) } & \text { TACGACGAGTCTTCC } \\ \text { AOX1 (sense) } & \text { AGGAGAAATGGATGACTAGATGCAT } \\ \text { AOX1 (antisense) } & \text { CATTGTAGGCTTCGTCGTGAAG } \\ \text { AOX1 (MGB-probe) } & \text { ATCCATAGCTGGTGTTCC }\end{array}$




\section{RESULTS}

Sensitivity of $\boldsymbol{C}$. albicans to Antifungal Drugs The sensitivity of $C$. albicans to antifungal drugs under aerobic and anaerobic conditions is shown in Fig. 1. For achieve anaerobic conditions, $\mathrm{Na}_{2} \mathrm{SO}_{3}$ (final $20 \mathrm{mg} / \mathrm{ml}$ ) was added to RPMI1640 medium. Sodium sulfite absorbs the oxygen dissolved in the RPMI1640 medium $\left(2 \mathrm{Na}_{2} \mathrm{SO}_{3}+\mathrm{O}_{2}=2 \mathrm{Na}_{2} \mathrm{SO}_{4}\right)$. The growth rate of $C$. albicans cells cultured under aerobic conditions was more markedly inhibited than that under anaerobic conditions by ciclopirox olamine, siccanin, neticonazole and amphotericin $\mathrm{B}$, but not terbinafine.

The sensitivity of $C$. albicans to various antifungal drugs at $\mathrm{pH} 3.9$ or $\mathrm{pH} 7.4$ is shown in Fig. 2. The acidic condition in the medium was prepared by addition of $1 \mathrm{~N} \mathrm{HCl}$ before the incubation and the $\mathrm{pH}$ was measured using ISFET $\mathrm{pH}$ METER KS501 (Shindengen Electric Manufacturing). The cultivation in $5 \% \mathrm{CO}_{2}$ did not affect the $\mathrm{pH}$ condition both in acidic (before $\mathrm{pH} 3.9$, after $\mathrm{pH} 3.9$ ) and neutral (before $\mathrm{pH}$ 7.4, after $\mathrm{pH}$ 7.4). Sensitivity of C. albicans against the drugs
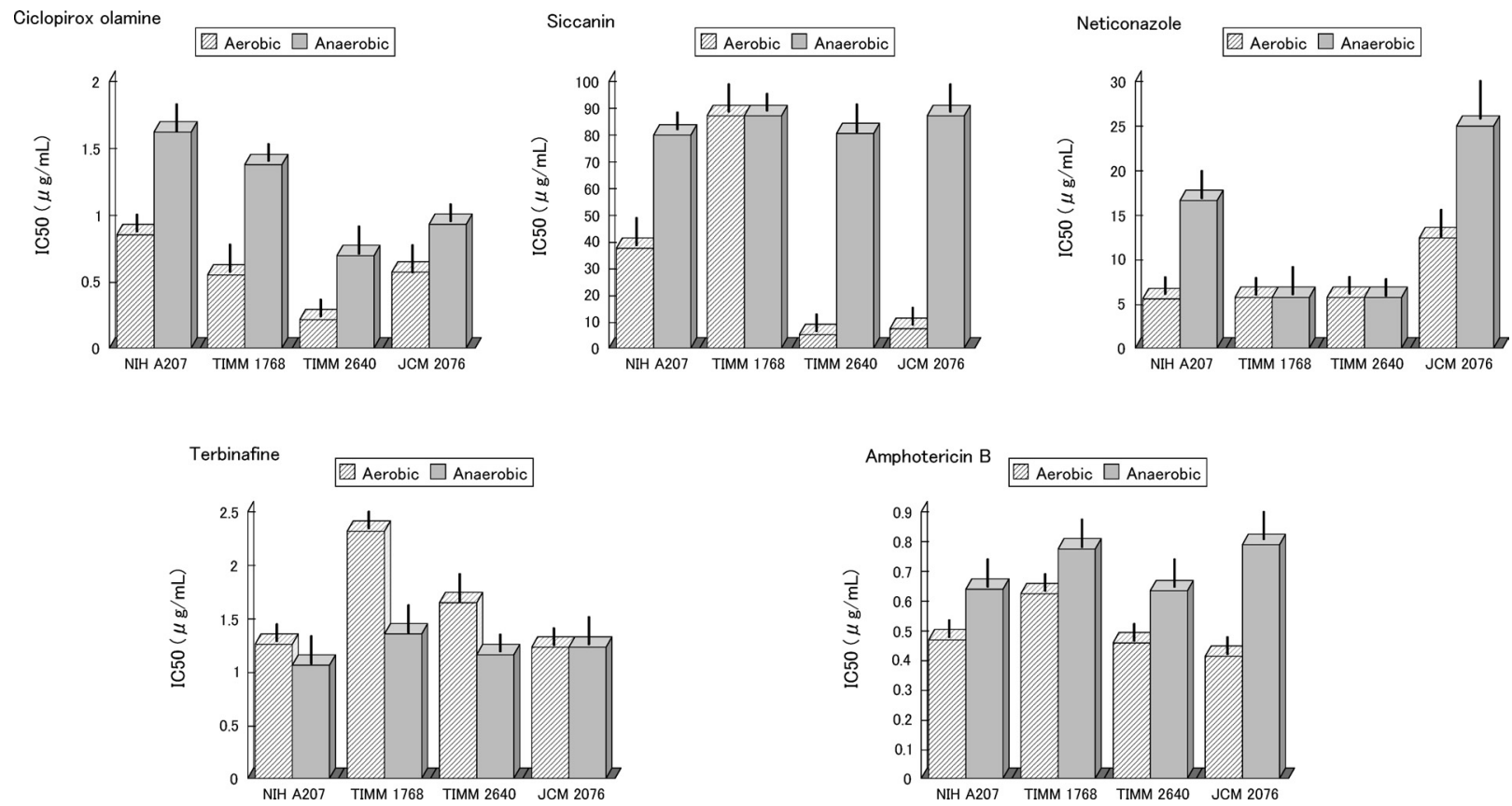

Fig. 1. Sensitivity of C. albicans to Antifungal Drugs under Aerobic or Anaerobic Conditions

Antifungal drugs were added to C. albicans NIH A207, TIMM1768, JCM2076 and TIMM2640 strains and the cells were incubated with/without sodium sulfite. After the incubation, the amount of C. albicans was measured as the absorbance at $620 \mathrm{~nm}$. Data represent the mean \pm S.E. $(n=4)$.

Ciclopirox olamine

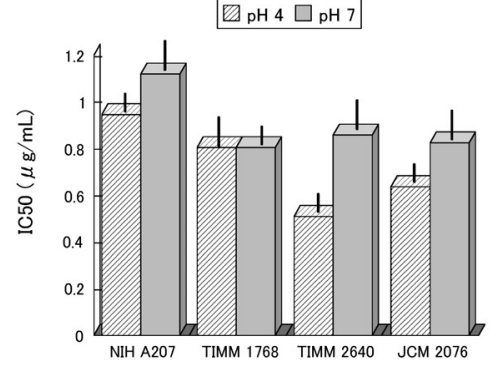

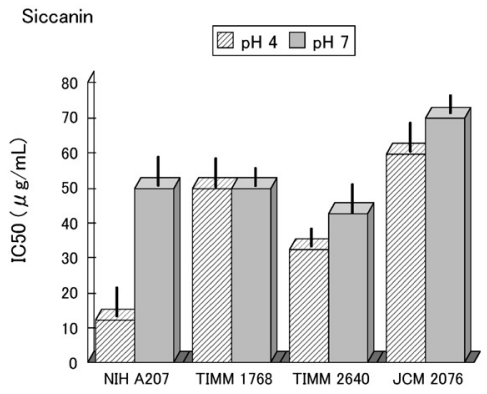







Fig. 2. Sensitivity of C. albicans to Antifungal Drugs at $\mathrm{pH} 4$ or $\mathrm{pH} 7$

Antifungal drugs were added to C. albicans NIH A207, TIMM1768, JCM2076 and TIMM2640 strains and the cells were incubated at pH 4 or pH 7 . After the incubation, the amount of $C$. albicans was measured as the absorbance at $620 \mathrm{~nm}$. Data represent the mean \pm S.E. $(n=4)$. 
Table 2. Growth Form of C. albicans NIH A207 Treated with Antifungal Drugs

\begin{tabular}{lccr}
\hline \hline & $\begin{array}{c}\text { Yeast cells } \\
\left(\times 10^{5} \text { cells } / \mathrm{ml}\right)\end{array}$ & $\begin{array}{c}\text { Total cells } \\
\left(\times 10^{5} \text { cells } / \mathrm{ml}\right)\end{array}$ & $\begin{array}{r}\text { Fraction } \\
\text { of yeast } \\
(\%)\end{array}$ \\
\hline None & $0.1 \pm 0.1$ & $43.0 \pm 6.0$ & 0.2 \\
Terbinafine $(1 \mu \mathrm{g} / \mathrm{ml})$ & $0.0 \pm 0.0$ & $37.0 \pm 3.0$ & 0.0 \\
Neticonazole $(1 \mu \mathrm{g} / \mathrm{ml})$ & $11.1 \pm 0.9$ & $14.0 \pm 5.0$ & 79.3 \\
Siccanin $(10 \mu \mathrm{g} / \mathrm{ml})$ & $0.2 \pm 0.1$ & $39.0 \pm 7.0$ & 0.5 \\
Ciclopirox olamine $(1 \mu \mathrm{g} / \mathrm{ml})$ & $0.2 \pm 0.1$ & $51.0 \pm 10.0$ & 0.4 \\
Amphotericin B $(0.125 \mu \mathrm{g} / \mathrm{ml})$ & $25.0 \pm 2.4$ & $48.5 \pm 4.3$ & 51.7
\end{tabular}

C. albicans was incubated with antifungal drugs for $24 \mathrm{~h}$. After the incubation, the fraction of yeast cells was measured as described in Materials and Methods. Data represent the mean \pm S.E. $(n=3)$.
Table 3. Levels of Hyphal Formation Signal mRNAs in C. albicans Treated with Antifungal Drugs

\begin{tabular}{|c|c|c|c|c|}
\hline & \multicolumn{4}{|c|}{ Relative level } \\
\hline & AOX1 & RAS1 & EFG1 & CPH1 \\
\hline None & $0.148 \pm 0.032$ & $0.726 \pm 0.109$ & $1.030 \pm 0.052$ & $0.875 \pm 0.083$ \\
\hline $\begin{array}{l}\text { Neticonazole } \\
\qquad(1 \mu \mathrm{g} / \mathrm{ml})\end{array}$ & $0.163 \pm 0.028$ & $0.590 \pm 0.317$ & $0.595 \pm 0.028 *$ & $0.475 \pm 0.043^{* *}$ \\
\hline $\begin{array}{l}\text { Terbinafine } \\
\qquad(1 \mu \mathrm{g} / \mathrm{ml})\end{array}$ & $0.007 \pm 0.004 *$ & $0.011 \pm 0.005^{*}$ & $0.025 \pm 0.002 *$ & $0.031 \pm 0.004 *$ \\
\hline $\begin{array}{r}\text { Amphotericin B } \\
(0.125 \mu \mathrm{g} / \mathrm{ml})\end{array}$ & $0.003 \pm 0.003^{*}$ & $0.001 \pm 0.001 *$ & $0.002 \pm 0.001 *$ & $0.001 \pm 0.001^{*}$ \\
\hline
\end{tabular}

C. albicans was incubated with antifungal drugs for $6 \mathrm{~h}$. After the incubation, the relative expression levels of mRNAs were measured as described in Materials and Methods. Data represent the mean \pm S.E. $(n=3) . * p<0.001 v$ s. none. $* * p<0.05 v$ s. none.



Control

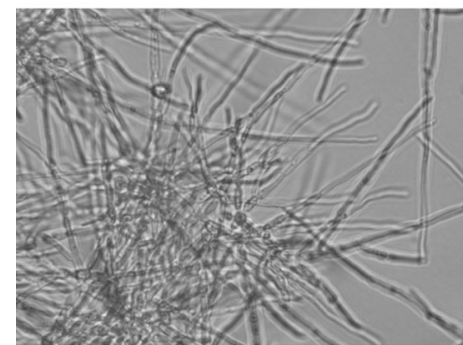

Siccanin $(10 \mu \mathrm{g} / \mathrm{mL})$

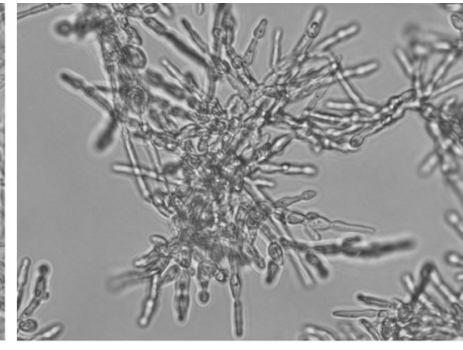

Terbinafine $(1 \mu \mathrm{g} / \mathrm{mL})$

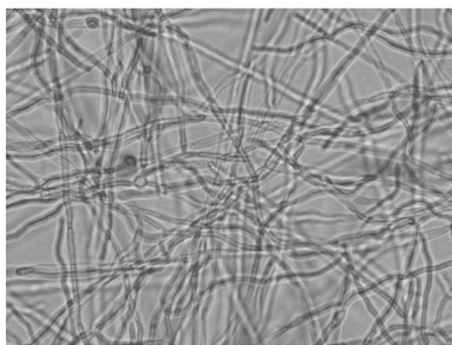

Ciclopirox olamine

$(1 \mu \mathrm{g} / \mathrm{mL})$

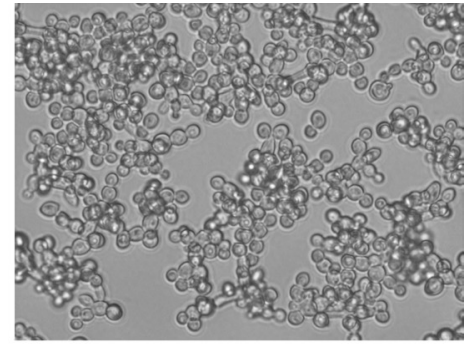

Neticonazole $(1 \mu \mathrm{g} / \mathrm{mL})$

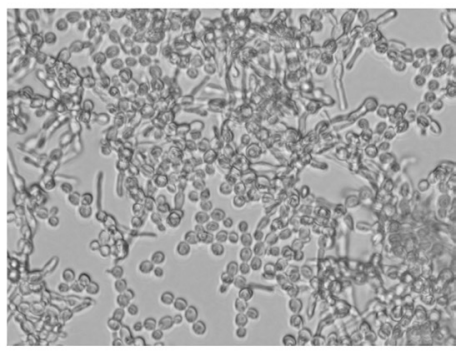

Amphotericin B

$(0.125 \mu \mathrm{g} / \mathrm{mL})$

Fig. 3. Growth Form of C. albicans Treated with Antifungal Drugs

C. albicans was incubated with antifungal drugs for $6 \mathrm{~h}$. After the incubation, the growth form of $C$. albicans was examined by photographing the cultures with a camera attached to an IX51 microscope (Olympus, $\times 400$ ).

was similar between pH 3.9 and $\mathrm{pH}$ 7.4.

Growth Form of $C$. albicans Treated with Antifungal

Drugs To examine the effect of antifungal drugs on the growth form of $C$. albicans, $C$. albicans cells were cultured in RPMI1640 with the drugs at $37^{\circ} \mathrm{C}$ for $6 \mathrm{~h}$. Although C. albicans grow in hyphal form in RPMI1640 medium, siccanin and ciclopirox olamine did not affect the growth form (Fig. 3). Terbinafine inhibited the elongation of hyphae cells, and neticonazole and amphotericin B inhibited the hyphal formation. Although the concentration of drugs used in this assay did not inhibit the growth of $C$. albicans, the fraction of yeast cells was significantly increased by neticonazole and amphotericin B (Table 2).

Analysis of the Hyphal Formation Signal in $C$. albicans Treated with Antifungal Drugs The hyphal formation of C. albicans is regulated by the MAP kinase cascade and cAMP pathway, which are activated by RAS1 protein. ${ }^{8)}$ The expression of CPH1, a component of the MAP kinase cascade, and EFG1, a component of the cAMP pathway, are increased during hyphal formation. Therefore, we measured the expression of the corresponding mRNAs (CPH1, EFG1 and RAS1) as indicators of the hyphal formation signal. $C$. albicans NIH A207 was cultured with various antifungal drugs and the levels of these mRNAs were measured using the 7500 Real Time PCR System and expressed relative to the level of $18 \mathrm{~S}$ rRNA (Table 3 ). The results showed that when the cells were cultured with terbinafine, neticonazole and amphotericin B, the expression of these mRNAs was inhibited.

\section{DISCUSSION}

In this study, the sensitivity of antifungal drugs to C. albicans cultured under aerobic and anaerobic conditions was measured. Ciclopirox olamine and siccanin were more effective in aerobic conditions than anaerobic ones (Fig. 1). These results indicated that these drugs should be more useful for treating superficial infection. Terbinafine, neticonazole and amphotericin B showed the same antifungal activity under both aerobic and anaerobic conditions. This suggests that 
these antifungal drugs might be effective against both superficial and deep-seated infection.

In general, the mouth is kept in a neutral condition with regard to $\mathrm{pH},{ }^{9)}$ while the vagina is kept in an acidic condition. ${ }^{10)}$ Therefore, we measured the difference of antifungal activities of these drugs under acidic and neutral conditions. As shown in Fig. 2, the antifungal activities were not affected by the $\mathrm{pH}$ of the culture medium, indicating that the antifungal drugs would have the same therapeutic effect under oral and vaginal conditions.

Moreover, we examined the growth form of $C$. albicans at non-cytocidal concentrations of the antifungal drugs to estimate the potential effects of the drugs on deep-seated C. albicans infection. Terbinafine inhibited the elongation of hyphae, whereas neticonazole and amphotericin B induced yeast proliferation (Fig. 3). The hyphae form of C. albicans is more pathogenic than the yeast form, at least in part because the yeast form of $C$. albicans is more easily eliminated by the defense system of the host. ${ }^{11)}$ These results suggest that non-cytocidal concentrations of these drugs would be able to eliminate $C$. albicans from the host.

As the expression of RAS1, EFG1 and CPH1 mRNAs was inhibited by these drugs (Table 3), the inhibition of hyphal formation might have been caused by the interruption of the RAS1-signal pathway.

\section{REFERENCES}

1) Yang Y. L., J. Microbiol. Immunol. Infect., 36, 223-228 (2003).

2) Favre B., Ghannoum M. A., Ryder N. S., Med. Mycol., 42, 525-529 (2004).

3) Nimura K., Niwano Y., Ishiduka S., Fukumoto R., Int. J. Antimicrob. Agents, 18, 173-178 (2001).

4) Matsumori N., Sawada Y., Murata M., J. Am. Chem. Soc., 127, $10667-10675$ (2005).

5) Niewerth M., Kunze D., Seibold M., Schaller M., Korting H. C., Hube B., Antimicrob. Agents Chemother, 47, 1805-1817 (2003).

6) D’Auria F. D., Tecca M., Strippoli V., Salvatore G., Battinelli L., Mazzanti G., Med. Mycol., 43, 391-396 (2005).

7) Bachewich C., Whiteway M., Eukaryot. Cell, 4, 95-102 (2005).

8) Van Nieuw Amerongen A., Veerman E. C., Ned. Tijdschr. Tandheelkd., 102, 443-445 (1995).

9) Makovitzki A., Shai Y., Biochemistry, 44, 9775-9784 (2005).

10) Torosantucci A., Chiani P., Cassone A., J. Leukoc. Biol., 68, 923-932 (2000).

11) Huh W. K., Kang S. O., J. Bacteriol., 181, 4098-4102 (1999). 